\title{
Metodologias baseadas em corpus para descrição de frames semânticos: desafios e possibilidades
}

\section{Corpus-based methodologies for description of semantic frames: challenges and possibilities}

Aline Nardes dos Santos*

Rove Chishman ${ }^{* *}$

\footnotetext{
* Doutora e mestra em Linguística Aplicada pela Unisinos. E-mail: aline.nardes@gmail.com

** Doutora e mestra em Linguística pela PUCRS. Professora titular da Unisinos; Bolsista de Produtividade do CNPq. E-mail: rove@unisinos.br

TradTerm, São Paulo, v.37, n. 1, janeiro/2021, p. 236-264

Número Especial - Linguística de Corpus www.revistas.usp.br/tradterm
} 
Resumo: Este artigo discute alguns caminhos metodológicos que têm sido adotados para descrição de frames semânticos com base em corpora. Para isso, parte da noção multifacetada de frame como construto sociocognitivo e como ferramenta analítica, por meio da qual é possível descrever e problematizar as conceptualizações que emergem em contextos sociais. Tendo como base as diferentes perspectivas metodológicas encontradas na literatura, o artigo desemboca de uma proposta delineada para uma tese de doutorado, que realizou um estudo de caso baseado em um corpus de audiências públicas. Como resultados, o artigo aponta para a necessidade de se considerar a pergunta de pesquisa, o tipo de corpus em estudo e o formato dos dados coletados para definição das etapas metodológicas que possibilitam a descrição de frames semânticos em diferentes contextos sociais.

Palavras-chave: Frames semânticos; Metodologias; Linguística de Corpus.

Abstract: This paper discusses some corpus-based methodological steps that have been adopted for the description of semantic frames. In this regard, it considers the multifaceted notion of frame as a socio-cognitive construct and as an analytical tool, by means of which it is possible to describe and to discuss conceptualizations that emerge from social contexts. Based on the different methodological perspectives found in literature, the paper finishes with a proposal designed for a doctoral thesis, which conducted a case study based on a corpus of public audiences. As results, the paper highlights the necessity of considering the research question, the type of study corpus and the format of the data collected for the definition of the methodological steps that enable the description of semantic frames in different social contexts.

Keywords: Semantic frames; Methodologies; Corpus Linguistics.

TradTerm, São Paulo, v.37, n. 1, janeiro/2021, p. 236-264

Número Especial - Linguística de Corpus www.revistas.usp.br/tradterm 


\section{Introdução}

A noção de frame semântico (FILLMORE, 1982, 1985) tem-se mostrado pertinente à análise de "[...] experiências sociais (na educação [...] ou em outros campos, como a saúde, a política, a segurança, a economia, a assistência, dentre outros) a partir dos discursos construídos por aqueles que vivem tais experiências sociais." (LIMA; MIRANDA, 2013, p. 11). Nesse âmbito, as propostas metodológicas de descrição de frames têm sido adaptadas e complementadas conforme a necessidade de cada pesquisa.

Mais especificamente, estudos na interface com a Semântica de Frames - seja para analisar interações face a face (MORATO et al., 2012, 2017), descrever estratégias discursivas em textos do domínio político (FREITAS, 2018; MORASSO, 2012), analisar experiências de sala de aula (LIMA, 2009; MIRANDA; LOURES, 2016), ou criar dicionários baseados em frames em uma interface com a lexicografia eletrônica (CHISHMAN et al. 2014, 2015, 2018; SANTOS; CHISHMAN, 2017) - têm retomado o convite à realidade de Fillmore presente em seus textos seminais, processo a partir do qual as propostas metodológicas de descrição de frames têm sido adaptadas e complementadas conforme a necessidade de cada pesquisa. No entanto, não há estudos na literatura sobre o tema que discutam e cotejem tais metodologias, analisando seus avanços, continuidades e descontinuidades, bem como discutindo o lugar da proposta da FrameNet - projeto de aplicação da Semântica de Frames iniciado pelo criador da teoria - em tal cenário.

Diante disso, este artigo objetiva discutir alguns caminhos metodológicos que têm sido adotados para descrição de frames semânticos com base em corpora. Para isso, partimos da noção multifacetada de frame como construto sociocognitivo (FILLMORE, 1985) e como ferramenta analítica (ZIEM, 2014), por meio da qual é possível descrever e problematizar as conceptualizações que emergem em contextos sociais. Tendo como base as diferentes perspectivas metodológicas encontradas na literatura, o artigo desemboca de uma proposta delineada para uma tese de doutorado, que realizou um estudo de caso baseado em um corpus de audiências públicas.

Com vistas a atingir seu propósito, o artigo está dividido em quatro

TradTerm, São Paulo, v.37, n. 1, janeiro/2021, p. 236-264 Número Especial - Linguística de Corpus www.revistas.usp.br/tradterm 
seções. A segunda seção, a seguir, aborda o percurso conceitual da noção de frame desde os textos seminais fillmorianos, defendendo o resgate de uma perspectiva mais sociocognitiva do construto. Na terceira seção, realizamos uma revisão da literatura atinente a percursos metodológicos encontrados em pesquisas que se utilizam do frame para analisar diferentes contextos sociais. Em seguida, tendo como base tais estudos, abordamos nossa proposta metodológica para identificação de frames no âmbito de uma tese doutoral (SANTOS, 2020), corroborando a necessidade de etapas que consideramos cruciais a estudos que se valem desse construto em uma perspectiva mais sociodiscursiva da linguagem.

\section{Por uma noção sociocognitiva de frame:} resgatando pressupostos fillmorianos

Quando o linguista George Lakoff introduz a noção de frame a seus alunos na Universidade de Berkeley, sua frase inicial é a seguinte: não pense em um elefante! É claro que, como o próprio exercício busca indicar, o que menos se consegue fazer ao se ouvir essa frase é evitar pensar em um elefante, pois a simples menção à palavra evoca todo o nosso conhecimento acerca de seu significado. Isso ocorre porque "Qualquer palavra, como elefante, evoca um frame, que pode ser uma imagem ou outros tipos de conhecimento: elefantes são grandes, têm orelhas frouxas e uma tromba, estão associados a circos, e assim por diante. A palavra é definida em relação a esse frame". (LAKOFF, 2004, p. 3, tradução nossa).

O clássico exemplo de Lakoff é emblemático para caracterizarmos o frame como estrutura de expectativa (TANNEN; WALLAT, 1993) e de conhecimento (MINSKY, 1981), que se constitui a partir de nossas experiências socioculturais e interacionais (MORATO, 2010). Por meio dessas estruturas sociocognitivas, que são constantemente manipuladas e partilhadas, compreendemos o mundo e sobre ele agimos (MORATO et al., 2017). Na Linguística, Charles Fillmore (1976a, 1982), inspirado nos trabalhos de Minsky (1981) e Goffman (1984), apropriou-se de tal construto para postular a teoria da Semântica de Frames - uma abordagem por meio da qual se compreende o

TradTerm, São Paulo, v.37, n. 1, janeiro/2021, p. 236-264 Número Especial - Linguística de Corpus www.revistas.usp.br/tradterm 
significado como resultante de "[...] formas estruturadas de se interpretar experiências [...]"às quais constantemente recorremos em interações sociais. (FILLMORE, 1976a, p. 20, tradução nossa). A exemplo disso, o termo "vegetariano(a)", de acordo com Fillmore (1976b, tradução nossa), é uma distinção culturalmente necessária somente em sociedades em que a maioria das pessoas se alimenta de carne: "[...] se todos no mundo se alimentassem apenas de comida vegetariana, não haveria necessidade da palavra 'vegetariano'." Desse modo, a noção fillmoriana de frame parte de uma perspectiva de linguagem centrada no uso (TOMASELLO, 2003), tendo em vista que ela se modifica constantemente para atender às necessidades comunicativas dos usuários.

Em sua dissertação de mestrado, Santos (2016) propôs-se a contar uma versão da "história dos frames de Fillmore", aproveitando seu próprio relato inicial da "história privada" desse conceito em sua trajetória (FILLMORE, 1982) e partindo de textos posteriores, com vistas a relacionar alguns marcos da vida acadêmica do autor aos desdobramentos de sua teoria. A partir desse delineamento, foi possível perceber que alguns aspectos de sua trajetória pessoal e profissional se refletiram nos rumos que sua teoria foi tomando ao longo dos anos. Nesse sentido, a Semântica de Frames consolidou-se após Fillmore aposentar-se da faculdade de Linguística da Universidade de Berkeley e instalar-se no Instituto Internacional de Ciência da Computação (ICSI) da mesma instituição. (JURAFSKY, 2014). Em tal contexto computacional, o pesquisador passou a desenvolver a FrameNet, uma plataforma lexicográfica baseada em frames que descreve o léxico da língua inglesa. Levando em conta as necessidades de áreas como Processamento de Linguagem Natural (PLN), Inteligência Artificial e Linguística Computacional, a FrameNet tem como foco a descrição de propriedades sintáticas e semânticas de palavras - as quais, no contexto do projeto, são denominadas unidades lexicais -, agrupando esse léxico em frames e sistematizando padrões de uso dessas unidades, os quais são legíveis por máquina. Para exemplificar esse processo descritivo, o quadro a seguir reproduz a definição do frame Ingestion:

TradTerm, São Paulo, v.37, n. 1, janeiro/2021, p. 236-264 Número Especial - Linguística de Corpus www.revistas.usp.br/tradterm 
Quadro 1 - Frame Ingestion

\section{Ingestion}

Definition:

An Ingestor consumes food or drink (Ingestibles), which entails putting the Ingestibles in the mouth for delivery to the digestive system. This may include the use of an Instrument. Sentences that describe the provision of food to others are NOT included in this frame.

The [wolves InGESTOR] DEVOURED [the carcass INGESTIBLE] completely.

Fonte: FrameNet (framenet.icsi.berkeley.edu).

As unidades lexicais que evocam o respectivo frame são sempre formatadas em realce preto - no exemplo acima, temos a unidade evocadora devoured. Marcados em negrito na definição e em versalete no exemplo do Quadro 1, estão os elementos de frame (EFs), os quais correspondem aos “[...] aspectos e componentes de cada frame que geralmente aparecem nas frases e sentenças que os instanciam.” (FILLMORE; BAKER, 2010, p. 321, tradução nossa). A exemplo disso, no quadro suprarreferido, a expressão The wolves instancia o EF Ingestor na frase "The wolves DEVOURED the carcass completely".

Assim, a descrição de cada unidade lexical indica os respectivos elementos de frame que ocorreram nas frases semanticamente anotadas provenientes de corpora autênticos em língua inglesa -, elencando também as realizações sintáticas de cada um desses elementos. Desse modo, a plataforma indica que a unidade lexical devour, que evoca o frame Ingestion, tem elencados os elementos de frame que coocorrem com ela em cada frase do corpus da FrameNet, bem como sua função sintática. Com base nos resultados desse processo de anotação, definem-se os padrões sintáticos dessa unidade lexical (vide Quadro 2). Dessa forma, as sentenças até o momento anotadas indicam que, na maioria dos casos analisados, devour coocorreu com o EF Ingestor na função sintática de sujeito e com o EF Ingestibles na função sintática de objeto direto, conforme exemplo metafórico a seguir: "On rainy days [he INGESTOR] DEVOURED [books INGESTIBLES]".

TradTerm, São Paulo, v.37, n. 1, janeiro/2021, p. 236-264

Número Especial - Linguística de Corpus

www.revistas.usp.br/tradterm 
Quadro 2 - Padrões valenciais da unidade lexical devour

\begin{tabular}{|c|c|c|c|}
\hline \multirow{3}{*}{$\begin{array}{l}\text { These frame element } \\
\qquad \begin{array}{c}\text { Number } \\
\text { Annotated }\end{array} \\
\underline{17} \text { TOTAL } \\
\end{array}$} & \multicolumn{3}{|c|}{ Ialence Patterns: } \\
\hline & \multicolumn{3}{|c|}{ Patterns } \\
\hline & Ingestibles & Ingestor & \\
\hline (1) & $\begin{array}{l}\text { NP } \\
\text { Ext }\end{array}$ & $\begin{array}{c}\mathrm{CNI} \\
--\end{array}$ & \\
\hline (6) & $\begin{array}{l}\text { NP } \\
\text { Ext }\end{array}$ & $\begin{array}{l}\text { PP[by] } \\
\text { Dep }\end{array}$ & \\
\hline (10) & $\begin{array}{l}\text { NP } \\
\text { Obj }\end{array}$ & $\begin{array}{l}\text { NP } \\
\text { Ext }\end{array}$ & \\
\hline$\underline{1}$ TOTAL & Ingestibles & Ingestor & Ingestor \\
\hline (1) & $\begin{array}{l}\text { NP } \\
\text { Obj }\end{array}$ & $\begin{array}{l}\text { NP } \\
\text { Ext }\end{array}$ & $\begin{array}{l}\text { NP } \\
\text { Ext }\end{array}$ \\
\hline
\end{tabular}

Fonte: Adaptado da FrameNet (framenet.icsi.berkeley.edu).

Diante de tal verticalidade descritiva, condicionada a necessidades lexicográfico-computacionais da FrameNet, delineia-se uma incômoda ruptura atinente ao conceito de frame semântico: ficando o frame da FrameNet condicionado à descrição das combinatórias sintático-semânticas, como inserir esse conceito em percursos metodológicos que não têm como objetivo central a descrição de valências? Como privilegiar questões sociocognitivas, incluindo as culturais e discursivas, se partirmos de um escopo computacional - ou, para retomar os exemplos que abriram esta seção, onde fica o caso do elefante? Do vegetariano? Das vicissitudes da experiência humana que nos levam a fazer escolhas linguísticas conforme certos “[...] propósitos discursivos, configuração institucional, eventos no mundo ao seu redor, posição no discurso, conhecimento compartilhado e todo o resto" (FILLMORE, 1980, p. 134, tradução nossa)? Como sintetiza Chishman (2019, p. 5), a visão enciclopédica dos frames, voltada às "[...] categorias de experiência subjacentes aos usos linguísticos [...]", não é privilegiada em uma perspectiva que tem como foco a descrição linguístico-computacional do léxico.

Nesse sentido, como aborda Santos (2020), os trabalhos seminais de Fillmore acerca da Semântica de Frames fazem um convite à realidade 
sociocultural e discursiva da linguagem que não é compreendido pela proposta da FrameNet. Com a plataforma, surge uma relevante noção de frame como ferramenta analítica (ZIEM, 2014) - ou seja como construto metodológico voltado à análise linguística, que complementa a noção de frame como esquema sociocognitivo -, mas cujas configurações não são pertinentes a pesquisas que buscam compreender "[...] práticas sociais em que a linguagem desempenha um papel central [...]" (MOITA LOPES, 2011, p. 22).

Tendo em vista esse aspecto, a seção a seguir realiza uma revisão da literatura atinente à descrição de frames semânticos, com base em corpora, em diferentes contextos sociais.

\section{Metodologias baseadas em corpora para descrição de frames em contextos sociais: revisão da literatura}

Nesta seção, abordamos as propostas metodológicas encontradas na literatura que identificam frames com base em corpora. Especificamente, após discutirmos a metodologia que sustenta o projeto lexicográficocomputacional da Semântica de Frames, articulamos algumas propostas encontradas em uma revisão da literatura que realizamos, com vistas a delinear um panorama metodológico que pudesse embasar uma proposta voltada ao estudo semântico-cognitivo de audiências públicas, conforme abordamos na seção 4. Destacamos que essas investigações, que foram buscadas em bases de dados nacionais e estrangeiras ${ }^{1}$, são majoritariamente de origem brasileira. Diante disso, consideramos que tais pesquisas, embora focadas em contextos diversos, ocupam-se de objetos de estudo calcados em nossa realidade cultural e discursiva, cujos resultados, portanto, também se prestam a indicar possíveis percursos de estudo em diversos corpora do português brasileiro.

\footnotetext{
1 Observamos que essas investigações foram coletadas por meio de buscas nas bases de dados EbscoHost, Portal de Periódicos da Capes, SciELO, Banco de Teses e Dissertações (BDTD), Catálogo de Teses e Dissertações da Capes e Google Acadêmico. As palavras-chave inseridas e cruzadas nessa busca (por meio do operador booleano "and"), em língua inglesa e portuguesa, foram: "semântica de frames", "sociocognição", "social" e "discurso".
}

TradTerm, São Paulo, v.37, n. 1, janeiro/2021, p. 236-264

Número Especial - Linguística de Corpus www.revistas.usp.br/tradterm 
Em contextos de Linguística Aplicada, como apontado na introdução, é necessária uma análise de frames que leve em conta a faceta enciclopédia desse construto, valorizando o continuum que existe entre aspectos macro e microcontextuais (MORATO, 2010) dos dados analisados. Dessa forma, além de uma exploração lexical do corpus, que permita a identificação de evocadores de frame, é preciso que tal percurso compreenda um estudo do domínio do qual emergem os frames (CHISHMAN et al., 2018).

Vale ressaltar que a própria metodologia de descrição de frames consolidada na versão contemporânea da Semântica de Frames - e aplicada à FrameNet - não tem como ponto de partida o léxico, pois se inicia com uma caracterização do frame previamente à investigação dos dados linguísticos, dado que tal construto, no caso de frames de língua geral, é conhecido e partilhado pelos falantes. Nesse sentido, elenco a seguir as principais etapas de identificação de frames postuladas pela versão mais contemporânea da teoria, quais sejam:

a) Caracterização do frame expresso linguisticamente, ou seja, do frame como tipo de situação "[...] para os quais a língua disponibiliza meios expressivos específicos” (FILLMORE; BAKER, 2010, p. 321, tradução nossa);

b) Descrição e nomeação dos elementos de frame, os quais constituem papéis semânticos recorrentes nas frases que instanciam esses frames (FILLMORE; BAKER, 2010, p. 321);

c) Seleção das unidades lexicais que evocam o frame;

d) Anotação semântica de frases provenientes do corpus, ou seja, “[...] atribuição de etiquetas de papéis temáticos a constituintes sintáticos [...]" dessas frases (FILLMORE; PETRUCK, 2003, p. 359, tradução nossa);

e) Geração automática de entradas lexicais, elencando todas as possibilidades de combinações sintático-semânticas - ou valências verificadas na etapa de anotação.

TradTerm, São Paulo, v.37, n. 1, janeiro/2021, p. 236-264 Número Especial - Linguística de Corpus www.revistas.usp.br/tradterm 
Em Santos (2016), tais etapas foram ilustradas a partir da figura do frame Vingança, conforme reproduzimos a seguir:

Figura 1 - Ilustração das etapas metodológicas da FrameNet

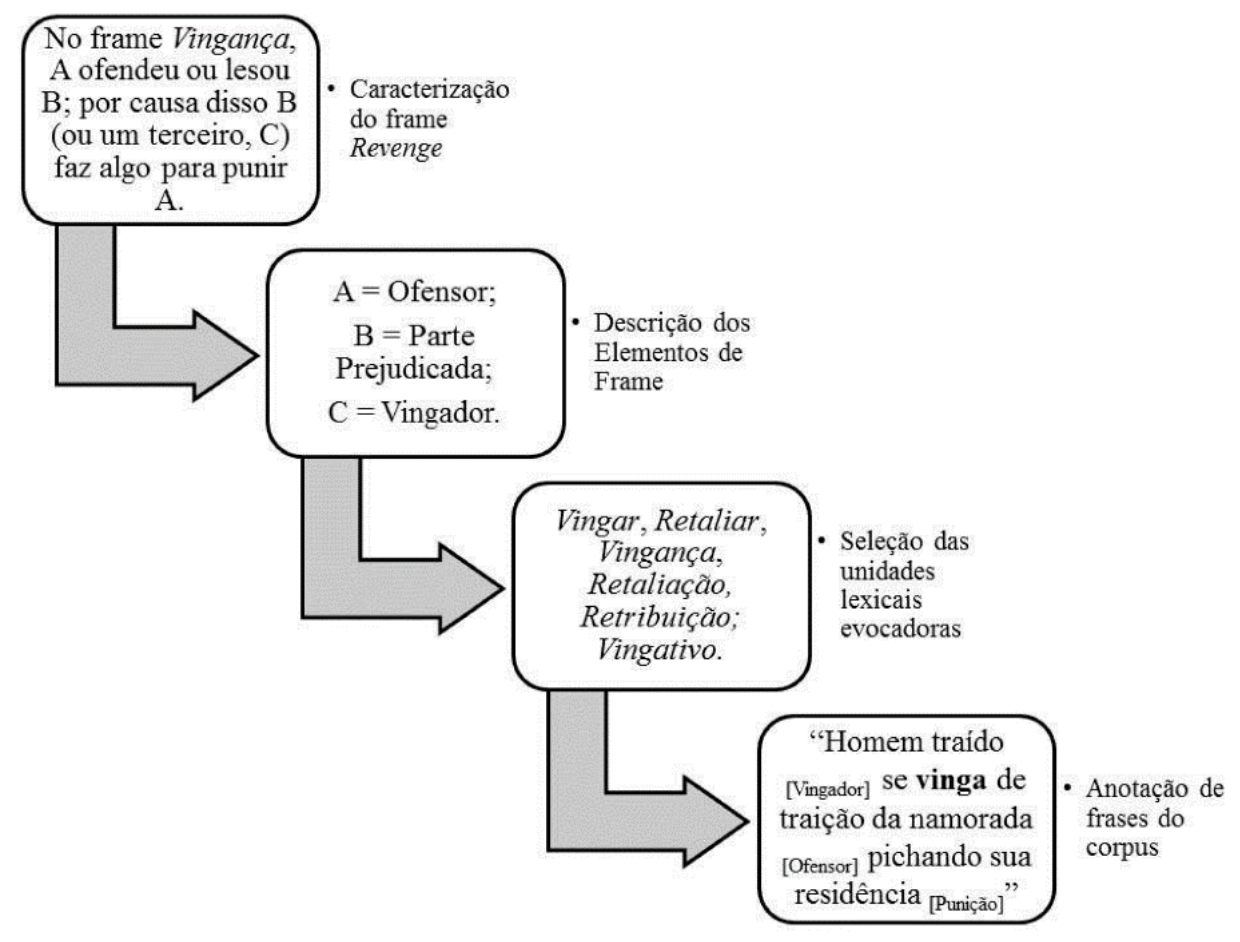

Fonte: Santos (2016, p. 54).

Assim, tal abordagem não parte inicialmente de dados linguísticos, pois considera o conhecimento prévio do falante para formular uma primeira versão do frame. É a partir dessa observação que o Grupo SemanTec tem adotado o termo middle-out para descrever a metodologia para identificação de frames que tem buscado consolidar (MÜLLER, 2015; CHISHMAN et al., 2018) - principalmente quando se trata da descrição de um domínio específico $^{2}$, que exige do(a) pesquisador(a) um estudo prévio do contexto investigado para então propor uma rede inicial de frames, que vai se aperfeiçoando e se remodelando conforme a pesquisa avança. Müller (2015, p. 101) explica o conceito de abordagem middle-out de identificação de frames:

2 O Grupo SemanTec tem avançado na descrição dos domínios jurídico (CHISHMAN et al., 2020), olímpico e paraolímpico (CHISHMAN et al., 2019).

TradTerm, São Paulo, v.37, n. 1, janeiro/2021, p. 236-264

Número Especial - Linguística de Corpus www.revistas.usp.br/tradterm 
É middle-out porque une as outras duas abordagens: ao elencarmos os conceitos organizando-os em um mapa conceitual do qual advêm os frames do domínio, estamos usando a abordagem top-down partindo dos conceitos mais amplos para especificá-los. E, ao listarmos as palavras relacionadas ao domínio e buscarmos suas relações com os conceitos, estamos seguindo a abordagem bottomup - do mais específico [...] para o mais amplo [...].

A opção por uma abordagem middle-out também vai ao encontro de outras pesquisas brasileiras que se utilizam do frame como ferramenta analítica para compreender diferentes experiências sociais. A exemplo disso, Morato et al. (2017), no contexto de interação entre afásicos e não afásicos, partem de um corpus de interações transcritas, que são segmentadas em tópicos discursivos (JUBRAN, 2006). A partir desses segmentos, os frames são identificados com base no conteúdo disponível na FrameNet Berkeley, a qual é usada, nesse contexto, como um dicionário. Também é feita a descrição de frames não disponíveis nessa base, bem como são detalhados alguns aspectos relativos às estruturas já descritas, se necessário.

Ainda em Morato et al. (2017), a partir da verificação do entrelaçamento de frames em cada tópico, os autores esquematizam e quantificam essa associação. Por exemplo, foi possível observar que, no segmento tópico "Dificuldade em evocar números", os frames mobilizados foram Memória, Meio e Situação de Dificuldade:

\begin{tabular}{|c|c|}
\hline $\begin{array}{l}\text { MEMÓRIA (baseado no frame } \\
\text { MEMORY } \\
\text { - FrameNet) }\end{array}$ & $\begin{array}{l}\text { Esse frame consiste em cognoscentes lembrando } \\
\text { e esquecendo um conteudo mental. }\end{array}$ \\
\hline $\begin{array}{l}\text { MEIO (baseado no frame MEIO - } \\
\text { FrameNet Brasil) }\end{array}$ & $\begin{array}{l}\text { Um agente faz uso de um meio - tanto uma ação } \\
\text { ou um sistema de entidades necessário para a } \\
\text { ação - a fim de se obter a finalidade. }\end{array}$ \\
\hline $\begin{array}{l}\text { SITUAÇÃO DE DIFICULDADE } \\
\text { (baseado no frame } \\
\text { PREDICAMENT - FrameNet) }\end{array}$ & $\begin{array}{l}\text { Um experienciador está em uma situação } \\
\text { de dificuldade, cuja causa também pode ser } \\
\text { expressa. }\end{array}$ \\
\hline
\end{tabular}

Fonte: Adaptado de Morato et al. (2017, p. 104).

De maneira convergente, as pesquisas de Lima e Miranda (2013), de Miranda e Bernardo (2013) e de Miranda e Loures (2016) partem de perguntas relevantes ao contexto educacional, que orientam suas pesquisas para a

TradTerm, São Paulo, v.37, n. 1, janeiro/2021, p. 236-264 Número Especial - Linguística de Corpus www.revistas.usp.br/tradterm 
exploração de um tema em específico - por exemplo, como os interagentes constroem o frame Aula em determinado ambiente escolar (LIMA; MIRANDA, 2013); quais são as experiências positivas e negativas dos alunos em escolas públicas (MIRANDA; BERNARDO, 2013); ou especificamente na aula de língua portuguesa? (MIRANDA; LOURES, 2016). Para ilustrar esse percurso, destacamos a pesquisa de Lima (2009), que buscou investigar a perspectiva discente do frame Aula por meio de um corpus de entrevistas, realizadas em escolas da rede pública municipal de ensino de Juiz de Fora - MG, com alunos de $6^{\circ}$ e $9^{\circ}$ anos. Assim como no trabalho de Morato et al. (2017), a autora utiliza a FrameNet Berkeley como parâmetro, de modo a esboçar uma primeira versão do frame Aula e complementá-lo segundo os elementos de frame emergentes das entrevistas. Considerando que as respostas obtidas já eram direcionadas ao frame a ser descrito ${ }^{3}$, o corpus pôde ser minuciosamente explorado por meio de uma lista de palavras - gerada a partir do software de corpus Wordsmith -, que serviu como ponto de partida para a verificação de evocadores e EF presentes nos dados.

Por meio de tal aporte, ao analisar a lexicalização dos EF Aula conforme sua realização sintática, foi possível verificar que os alunos entrevistados se colocavam muito mais no papel de pacientes nesse cenário, e não de agentes. Segue um exemplo de evocação do frame Aula em que o professor é colocado como agente pelos discentes:

"Uma aula é o professor explicar, dar matéria, fazer o dever e o mais importante: aprender o que o professor passou o ano inteiro."

Assim, um dos principais resultados de sua pesquisa indica que "A contradição existente entre a definição do frame Aula e a descrição das ações discentes revela que o aluno, por se ver tal como a sociedade o vê, como Paciente da interação, não percebe em si o perfil de um agente transformador da realidade." (LIMA, 2009, p. 142).

De modo geral, quanto à utilização da FrameNet como parâmetro para identificação de frames nos trabalhos encontrados, é interessante observar

\footnotetext{
${ }^{3}$ As questões que os alunos responderam foram as seguintes: "Para você, o que é uma aula?"; " $O$ que os seus professores fazem nas aulas? $O$ que vocês, alunos, fazem nas aulas? Dê exemplos de suas ações mais comuns, frequentes ou rotineiras."; "Para você, o que é um boa aula?". (LIMA, 2009, p. 78).
}

TradTerm, São Paulo, v.37, n. 1, janeiro/2021, p. 236-264 Número Especial - Linguística de Corpus www.revistas.usp.br/tradterm 
alguns cuidados relativos ao uso parcimonioso da plataforma. Por exemplo, conforme observa Siman (2015, p. 5), a Semântica de Frames, por meio do Projeto FrameNet, foi utilizada em sua pesquisa "[...] como referência (mas não como limite) para as análises e discussões produzidas [...]", visto que o projeto lexicográfico de Fillmore, embora seja muito rico em descrições da língua inglesa que podem ser adaptadas a análises em língua portuguesa, não dá conta da complexidade de domínios especializados, fator que demanda a criação de novos frames conforme a necessidade do(a) analista.

De modo geral, tais pesquisas inseridas no âmbito da Linguística Aplicada sugerem o enriquecimento das etapas metodológicas postuladas pela FrameNet, por meio de alguns aspectos destacados a seguir:

a) Tais investigações apontam a pertinência da realização de um estudo do domínio que elenque as características do contexto investigado - por exemplo, o Grupo SemanTec elabora mapas conceituais dos esportes previamente à descrição de frames (CHISHMAN et al., 2018);

b) Se a pergunta de pesquisa é anterior à compilação do corpus, é importante delinear um projeto de corpus que responda ao problema investigado e permita a identificação dos frames de acordo com os objetivos estabelecidos - é o caso dos trabalhos de Miranda e Bernardo (2013) e de Lima (2009), que geram seus dados por meio de entrevistas estruturadas de acordo a pergunta de pesquisa;

c) Se a pergunta de pesquisa parte de um corpus em específico, é relevante segmentá-lo de acordo com o estudo do domínio e com o objetivo da investigação, de modo a descrever os frames a partir desse mapeamento - é o caso de pesquisas como a de Morato et al. (2017), que divide os dados a partir da noção de tópico.

Tomando como base as investigações aqui revisadas, na próxima seção, descrevemos e discutimos uma proposta metodológica para descrição de frames delineada para uma tese de doutorado, que realizou um estudo de caso baseado em um corpus de audiências públicas, para então sintetizarmos

TradTerm, São Paulo, v.37, n. 1, janeiro/2021, p. 236-264 Número Especial - Linguística de Corpus www.revistas.usp.br/tradterm 
algumas etapas essenciais a percursos metodológicos baseados em corpora, no que se refere à identificação de frames semânticos.

\section{A Sugestão Legislativa $n^{\circ}$ 15/2014: proposta metodológica de descrição de frames voltada a audiências públicas}

Com base em tais percursos metodológicos, no contexto de uma tese doutoral, investigamos a emergência de frames semânticos em audiências públicas da Sugestão Legislativa $n^{\circ} 15 / 2014$, que visou a regular a interrupção da gravidez até as 12 semanas de gestação. 0 objetivo foi compreender, por meio da identificação de diferentes instanciações de frames que emergem nesse contexto, as redes de significado que (re)enquadram os direitos humanos e reprodutivos das mulheres sob diferentes perspectivas.

A investigação configurou-se como um estudo de caso, pois sua análise ficou restrita a um objeto específico, "[...] de maneira a permitir o seu conhecimento amplo e detalhado." (GIL, 2008, p. 58). Mais especificamente, a análise se restringiu às transcrições das audiências públicas, disponibilizadas no formato de atas de reunião, que debateram a Sugestão Legislativa $n^{\circ} 15$ entre maio de 2015 e abril de 2016. Tais registros permaneceram disponíveis no Portal e-Cidadania enquanto a Sugestão tramitava no Senado. Os cinco arquivos - um para cada audiência - foram disponibilizados no formato RTF (Rich Text Format), que é compatível com todas as versões do Microsoft Word e com editores mais simples, como o WordPad.

Ao todo, o corpus na íntegra tem pouco mais de 140 mil palavras, totalizando cerca de 230 páginas. ${ }^{4}$ Considerando a extensão média do material, que pode ser considerado um corpus pequeno (BERBER SARDINHA, 2000), foi possível fazer uma leitura integral dos dados antes de começar a manipulá-los. Ao encontro disso, Koester (2010, p. 67) elenca as seguintes vantagens de se trabalhar com corpora pequenos em contextos de estudo de linguagens de especialidade:

\footnotetext{
${ }^{4}$ Considerando uma lauda com fonte Arial 12, com espaçamento simples.

TradTerm, São Paulo, v.37, n. 1, janeiro/2021, p. 236-264

Número Especial - Linguística de Corpus

www.revistas.usp.br/tradterm
} 
[...] eles permitem um elo mais forte entre o corpus e os contextos nos quais os textos do corpus foram produzidos. Enquanto corpora muito grandes, por meio de sua descontextualização, trazem esclarecimentos quanto a padrões léxico-gramaticais na língua como um todo, corpora pequenos e especializados fornecem informações sobre padrões de uso linguístico em contextos específicos. (Tradução nossa).

Essa etapa do processo de preparação do corpus a partir de uma leitura preliminar ainda incluiu o mapeamento dos participantes (processo cujos resultados são explorados na primeira parte de nossa análise) de acordo com sua categoria de participação. Inicialmente, separamos os convidados panelistas e os demais participantes das sessões nas grandes categorias "próSUG" e "anti-SUG" - ou seja, consideramos que aqueles que defendem a regulação do aborto nas 12 primeiras semanas de gestação como pró-SUG; e aqueles que se opõem à proposta, como anti-SUG. Ao todo, chegamos a um total de 78 participantes. Após esse mapeamento, considerando a primeira leitura do material, organizamos quadros com uso do Microsoft Excel, no qual sistematizamos dados como nome do participante; papel institucional; posicionamento em relação à SUG (contra ou a favor da proposta); e resumo da sua exposição em uma frase.

Para escolhermos o ferramental necessário a uma análise de frames que levasse em conta um continuum entre aspectos macro e microcontextuais (MORATO, 2010), compreendendo um estudo do domínio, estabelecemos como critério a necessidade de recursos que não apenas nos permitissem a exploração lexical do corpus, mas que também viabilizassem um estudo do domínio no qual emergem os frames (CHISHMAN et al., 2018), tendo em vista as categorias previamente elencadas no estudo preliminar do corpus - tais como posicionamento em relação à SUG e função institucional. Diante disso, optamos por utilizar uma ferramenta de análise qualitativa dos dados que nos permitisse ter uma visão mais ampla de nosso corpus, bem como classificar os dados por meio de diferentes categorias temáticas. Trata-se do QSR NVivo, um software que permite o cruzamento de diversos parâmetros que classificam qualitativamente os dados. A figura a seguir exibe a interface do

TradTerm, São Paulo, v.37, n. 1, janeiro/2021, p. 236-264 Número Especial - Linguística de Corpus www.revistas.usp.br/tradterm 
programa. ${ }^{5}$ A versão que utilizamos se chama NVivo 12 Pro.

Figura 3 - Tela inicial do QSR NVivo

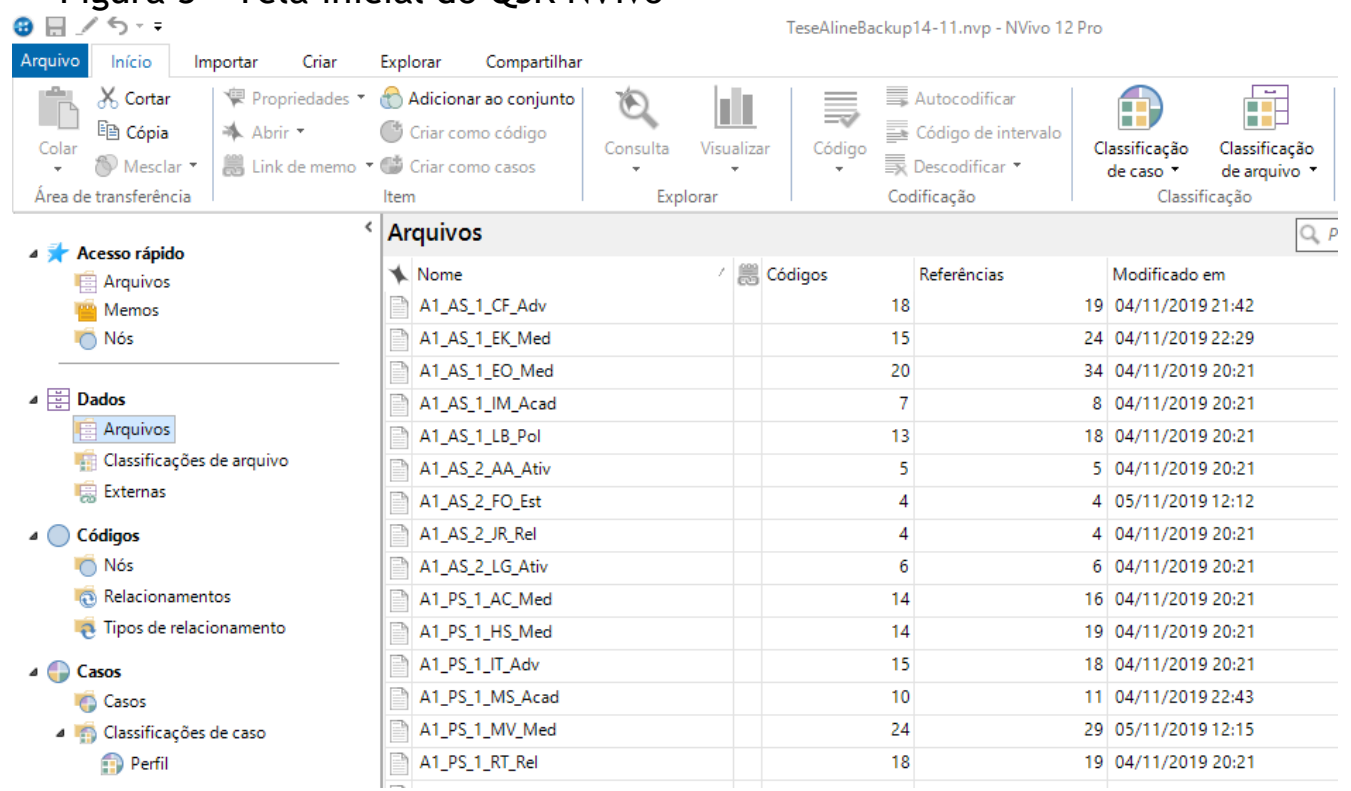

Fonte: Santos (2020, p. 121).

Ao se abrir um dos arquivos de transcrição, é possível marcar excertos do texto e classificá-los nos chamados nós, que "[...] representam uma categoria ou ideia abstrata [...]" criada pelo pesquisador. (GUIZZO; KRZIMINSKI; OLIVEIRA, 2003, p. 57). No caso de nossa análise, tal recurso foi bastante útil para identificarmos os grandes temas abordados em cada participação. Salientamos ainda que os próprios nós deram origem a pequenos subcorpora separados por temas, dentre os quais os maiores (com mais de vinte excertos) foram também processados na ferramenta de corpus, com vistas a explorarmos o léxico de forma mais ampla e confirmarmos possíveis evocadores de frames.

Embora o NVivo disponha de um recurso simplificado para busca textual, optamos por explorar o léxico com uma ferramenta de corpus que nos oferecesse uma pesquisa mais completa de unidades linguísticas - o Sketch Engine, um software eficiente na manutenção de corpus que tem sido utilizado pelo grupo SemanTec em suas pesquisas linguísticas, mostrando-se

\footnotetext{
${ }^{5}$ Uma licença para estudantes foi adquirida pelo Grupo SemanTec, a qual tem validade de dois anos. Agradecemos à Fundação de Amparo à Pesquisa do Estado do RS (Fapergs) pela concessão dos recursos que viabilizaram tal aquisição.
}

TradTerm, São Paulo, v.37, n. 1, janeiro/2021, p. 236-264 Número Especial - Linguística de Corpus www.revistas.usp.br/tradterm 
um profícuo recurso para exploração do léxico em estudos que visam a identificar frames semânticos. (CHISHMAN et al., 2014, 2015, 2018; SANTOS; CHISHMAN, 2017).

Para processamento dos dados, o corpus foi carregado para a ferramenta no formato docx. O recurso fez a compilação automática do material, utilizando o etiquetador Freeling, que atribui etiquetas sintáticas aos termos para facilitar buscas por combinatórias. À parte das falas protocolares, que foram excluídas dos dados processáveis e fazem parte apenas da primeira etapa de análise, o tamanho do corpus é de 114.429 palavras.

Especificamente, os recursos do programa que utilizamos são elencados na sequência:

a) Keywords: extrai uma lista das palavras-chave do corpus de estudo, ou seja, aquelas que são estatisticamente mais proeminentes;

b) Concordance: permite a visualização da palavra pesquisada, ou palavra-nó, juntamente com o texto adjacente, ou cotexto;

c) Sketch Difference: permite a comparação entre as combinatórias de uma palavra no corpus como um todo, ou entre o uso do mesmo item lexical em diferentes subcorpora.

Considerando os objetivos do estudo, organizamos nosso percurso analítico em três etapas, a partir de questionamentos que também refletem os objetivos específicos estabelecidos.

a) Como se estrutura o contexto institucional da SUG 15?: essa etapa de análise envolveu o uso do QSR NVivo para efetuar os seguintes passos:

- mapeamento de todos os participantes das audiências, bem como de seus papéis institucionais;

- levantamento dos diferentes grupos institucionais presentes e de sua representatividade em termos numéricos;

- delineamento das relações hierárquicas que permeiam a estrutura

TradTerm, São Paulo, v.37, n. 1, janeiro/2021, p. 236-264 Número Especial - Linguística de Corpus www.revistas.usp.br/tradterm 
das audiências da SUG.

Essa etapa do percurso analítico permitiu-nos identificar o privilégio dado aos parlamentares (em sua maioria, os presentes eram contrários à matéria) para se manifestarem a qualquer momento nas audiências; o papel do relator da Sugestão como autoridade que pode ser convencida pelos participantes de acordo com o poder de persuasão - aspecto que não se sustenta quando se verifica que seu posicionamento contrário à Sugestão sempre foi evidente -; e a constituição hierárquica da SUG, que coloca o relator e os demais parlamentares em um nível superior aos demais participantes. Assim, a configuração das audiências já se mostra sobredeterminante (HANKS, 2008) no que se refere ao (limitado) espaço que seus defensores tiveram para defender a pauta.

b) Quais são as temáticas, ou os nós, que estão presentes nas falas dos participantes?: considerando o funcionamento da ferramenta NVivo, a qual exige a classificação do corpus em nós para processar inter-relações com as demais categorias, valemo-nos desse recurso para mapear as grandes temáticas que constituem as audiências, por meio dos seguintes passos:

- releitura de cada arquivo do subcorpus após inseri-lo na interface do NVivo;

- seleção dos excertos que correspondem a um grande tema e criação do nó correspondente na ferramenta;

- processamento integrado de todos os nós e verificação de sua predominância nas audiências como um todo.

Essa etapa evidenciou as aproximações e os distanciamentos entre os temas abordados pelos grupos pró-SUG e anti-SUG, bem como já apontou para a preponderância dos temas Origem da Vida e Riscos do Aborto (nesse caso, do abortamento em geral) no corpus como um todo. Trata-se de temas que, além de serem os mais abordados, também são representativos do corpus anti-SUG.

TradTerm, São Paulo, v.37, n. 1, janeiro/2021, p. 236-264 Número Especial - Linguística de Corpus www.revistas.usp.br/tradterm 
c) A partir das temáticas identificadas, quais são os frames que emergem dessas comunicações? Quais itens lexicais os evocam?: essa etapa de análise envolveu o uso da ferramenta Sketch Engine e compreendeu estes procedimentos:

- identificação das unidades lexicais que potencialmente evocam frames, considerando os nós elencados na etapa anterior - para os nós com mais de vinte excertos, consulta às palavras-chave do respectivo subcorpus no Sketch Engine;

- busca dessas unidades lexicais na FrameNet e/ou de frames relacionados e, se necessário, descrição de novo frame;

- descrição dos Elementos de frame instanciados nas concordâncias;

- sistematização das unidades linguísticas que instanciam evocadores e elementos de frame, por meio do uso dos recursos da ferramenta Sketch Engine;

- se necessário, refinamento da descrição do frame a partir dos dados encontrados por meio da ferramenta de corpus.

Para exemplificar esse percurso, ilustramos a seguir a identificação e exploração do frame Responsabilidade, originado do nó homônimo. Trata-se de excertos atinentes à responsabilidade de diferentes atores envolvidos na questão do aborto (mulher, marido, Estado etc.). No NVivo, todos esses excertos foram atribuídos ao respectivo nó, conforme reproduzido a seguir:

TradTerm, São Paulo, v.37, n. 1, janeiro/2021, p. 236-264 Número Especial - Linguística de Corpus www.revistas.usp.br/tradterm 
Figura 4 - Exemplo de atribuição de um excerto do corpus ao nó Responsabilidade

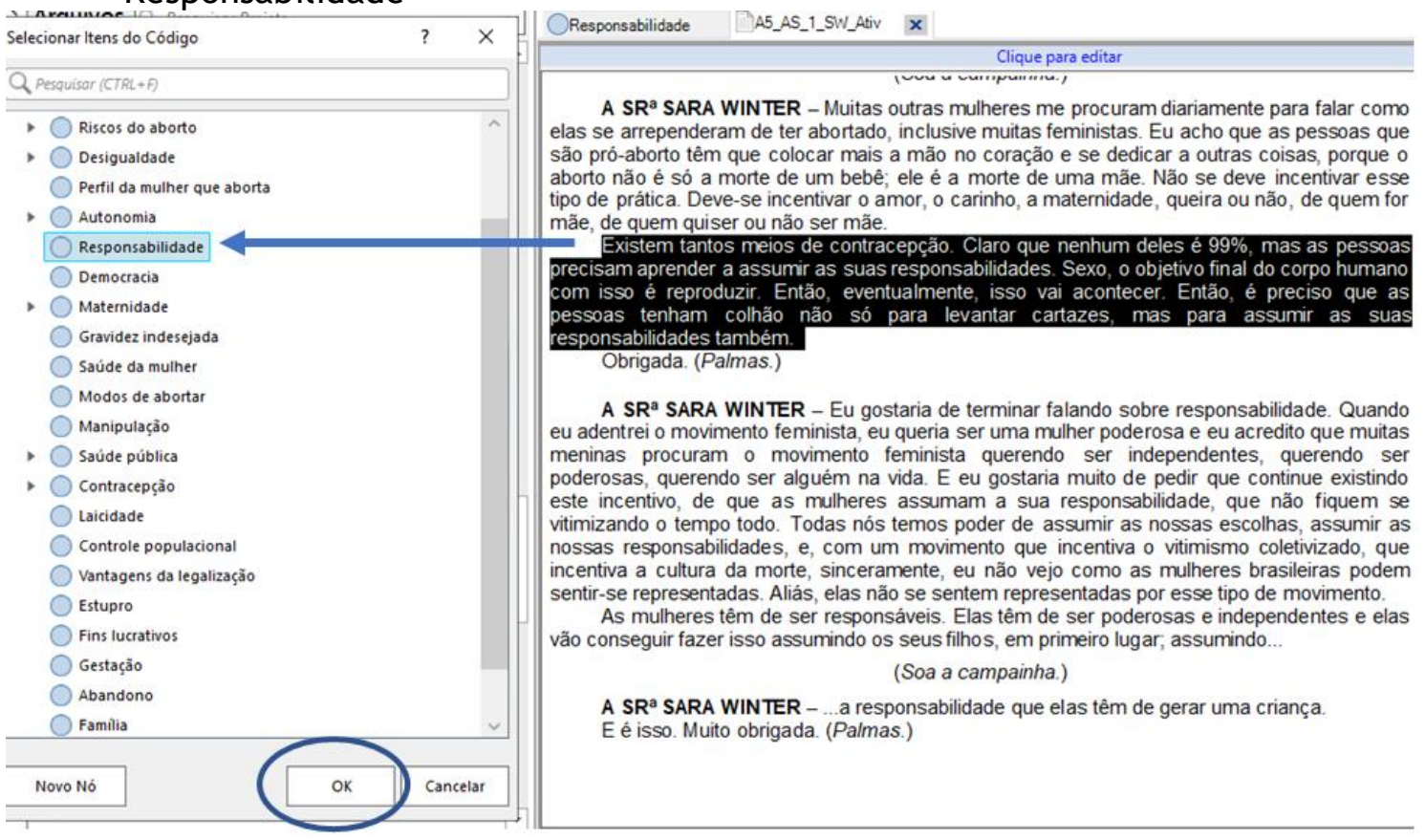

Fonte: Santos (2020, p. 122).

Ao processarmos no Sketch Engine os excertos atribuídos ao nó Responsabilidade, que constituíram um subcorpus, extraímos da lista de palavras-chave os possíveis evocadores de frame, quais sejam: assumir a responsabilidade, responsáveis, assumir as consequências, obrigação e responsabilização. Realizando o procedimento de anotação semântica, definimos esse frame conforme sua evocação nos subcorpora Pró-SUG e AntiSUG, respectivamente, conforme quadro bipartido a seguir. 
Quadro 3 - O frame Responsabilidade nos subcorpora Pró-SUG e Anti-SUG

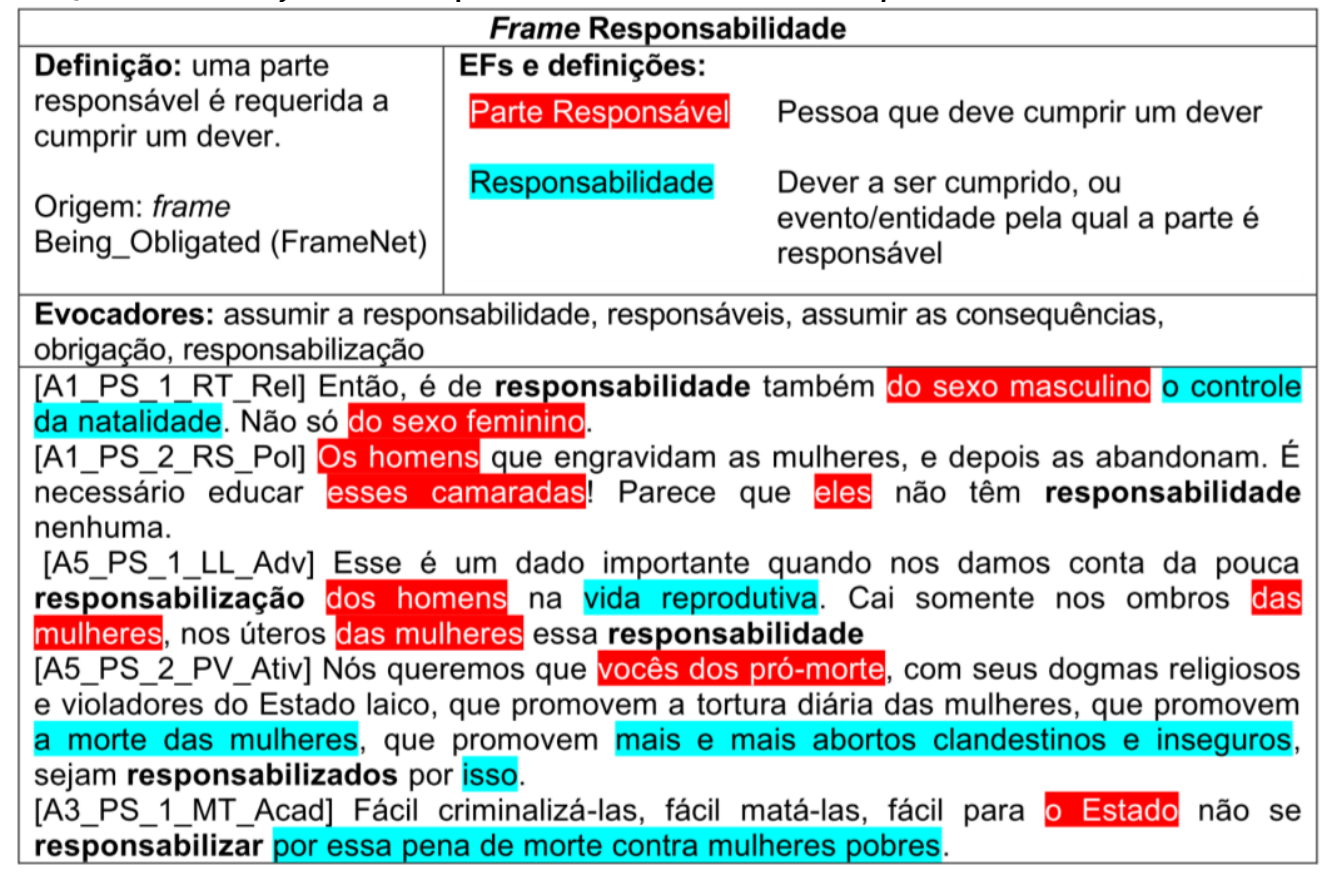

\begin{tabular}{|c|c|c|}
\hline \multicolumn{3}{|c|}{ Frame Responsabilidade } \\
\hline $\begin{array}{l}\text { Definição: uma parte responsável é } \\
\text { requerida a cumprir um dever. }\end{array}$ & $\begin{array}{l}\text { EFs e definições: } \\
\text { Parte Responsável }\end{array}$ & $\begin{array}{l}\text { Pessoa que deve cumprir } \\
\text { um dever } \\
\text { Dever a ser cumprido, ou } \\
\text { evento/entidade pela qual } \\
\text { a parte é responsável }\end{array}$ \\
\hline \multicolumn{3}{|c|}{$\begin{array}{l}\text { Evocadores: assumir a responsabilidade, responsáveis, assumir as consequências, } \\
\text { obrigação, responsabilização }\end{array}$} \\
\hline \multicolumn{3}{|c|}{$\begin{array}{l}\text { [A5_AS_1_SW_Ativ] Existem tantos meios de contracepção. Claro que nenhum deles é 99\%, } \\
\text { mas as pessoas precisam aprender a assumir as suas responsabilidades. } \\
\text { [A5_AS_1_SW_Ativ] As mulheres têm de ser responsáveis. Elas têm de ser poderosas e } \\
\text { independentes e elas vão conseguir fazer isso assumindo os seus filhos, em primeiro lugar } \\
\text { [A1_AS_1_EK_Med] a gente acredita e espera que, pela educação, os homens aprendam } \\
\text { gradativamente a respeitar e a assumir a responsabilidade, e as mulheres também } \\
\text { [A1_AS_1_EO_Med] a relação entre o pail, a mãe e o bebê é de responsabilidade. } \\
\text { [A2_AS_2_RL_Adv] Inventaram até a camisinha feminina, porque não querem imputar só ao } \\
\text { homem a obrigação de não engravidar. A mulher também tem sua obrigação. } \\
\text { Elas querem o quê? Poder fazer sexo ilícito e não assumir com as suas responsabilidades. }\end{array}$} \\
\hline
\end{tabular}

Fonte: adaptado de Santos (2020, p. 164, 211).

Tais contrastes foram corroborados por meio do processamento do evocador responsabilidade no recurso Sketch Difference: verificamos que os pró-SUG são os únicos que combinam esse termo com os itens "parlamentares"6, “pai”, "senado"7, "Ministério"8 e "Estado", conforme

${ }^{6}$ Concordância: "Então, queria chamar a atenção e a responsabilidade dos nossos Parlamentares, das Casas Legislativas e das Lideranças políticas [...]".

7 Concordância: "[...] coloca também a responsabilidade do Senado Federal em fazer este debate $[. .]$.$" .$

TradTerm, São Paulo, v.37, n. 1, janeiro/2021, p. 236-264 Número Especial - Linguística de Corpus www.revistas.usp.br/tradterm 
exibimos na figura a seguir (coluna à esquerda). São também os únicos que falam em responsabilidade social e pública (vide coluna à direita). Já os antiSUG tratam apenas de responsabilidade penal (em uma ocorrência, conforme coluna à direita).

Figura 5 - Sketch Difference para a palavra responsabilidade

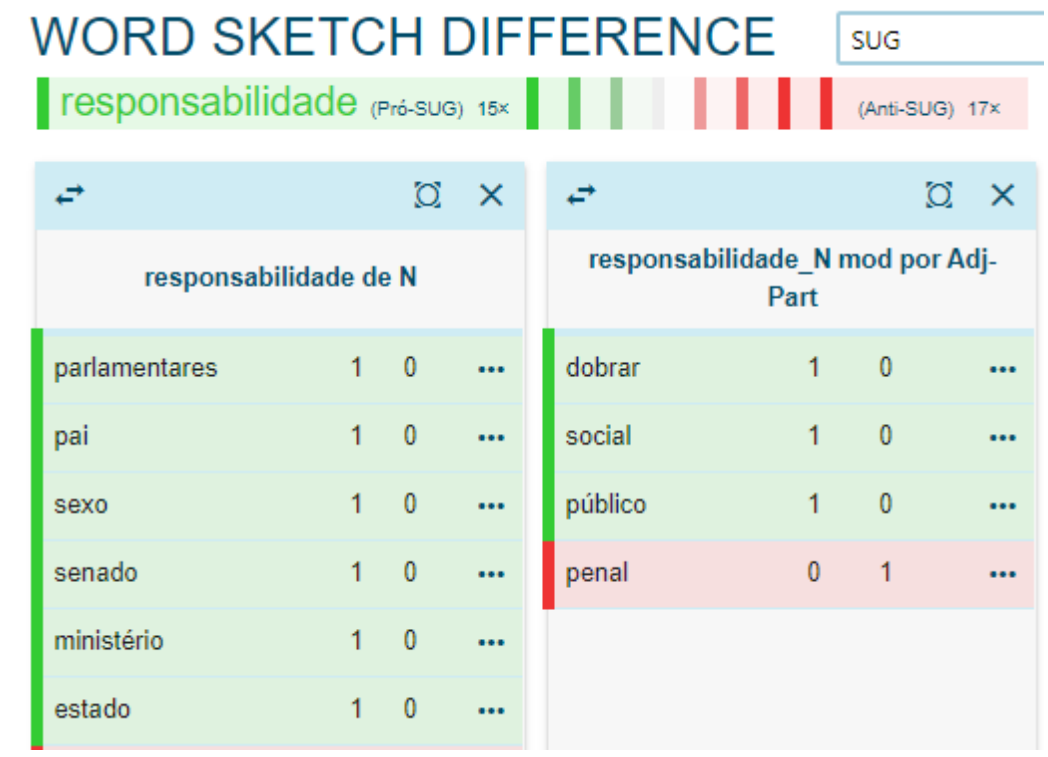

Fonte: Santos (2020, p. 165).

A partir de frames como esse, os participantes pró-SUG conceptualizam a criminalização do aborto como mecanismo ineficaz para reduzir o número de abortamentos clandestinos. Além disso, enquanto os pró-SUG enfatizam a corresponsabilidade entre homens e mulheres pela contracepção (vide Quadro 3 , parte superior), alguns participantes anti-SUG consideram que a mulher é a única responsável nessa situação. Nesse sentido, apenas em três excertos de tal subcorpus se verifica uma relação de responsabilidade que inclui "pai e mãe", "homens e mulheres”, ou "as pessoas" em geral (vide Quadro 3, parte inferior). Nas demais ocorrências, o foco recai sobre a responsabilidade maior (ou única) das mulheres sobre a contracepção. Além disso, chega-se a atribuir à mulher a responsabilidade por "assumir seus filhos" no caso de uma gestação indesejada. Consequentemente, conceptualiza-se o abortamento como ato que decorre da irresponsabilidade das mulheres.

${ }^{8}$ Concordância: “[...] atenção humanizada ao abortamento. É da responsabilidade do Ministério da Saúde fazer isso."

TradTerm, São Paulo, v.37, n. 1, janeiro/2021, p. 236-264

Número Especial - Linguística de Corpus

www.revistas.usp.br/tradterm 
A imagem a seguir esquematiza as distintas instanciações do frame Responsabilidade, considerando os contrastes entre os diferentes modos pelos quais os pró-SUG (balões à esquerda) e os anti-SUG (balão à direita) agenciam o mesmo frame. Nesse âmbito, destacamos também que os pró-SUG instanciam o EF Parte Responsável com expressões referentes ao Estado, no que se refere à morte de mulheres. Já os anti-SUG evocam esse frame para tratar somente de responsabilidade contraceptiva e parental.

Figura 6 - Perspectivações do frame Responsabilidade

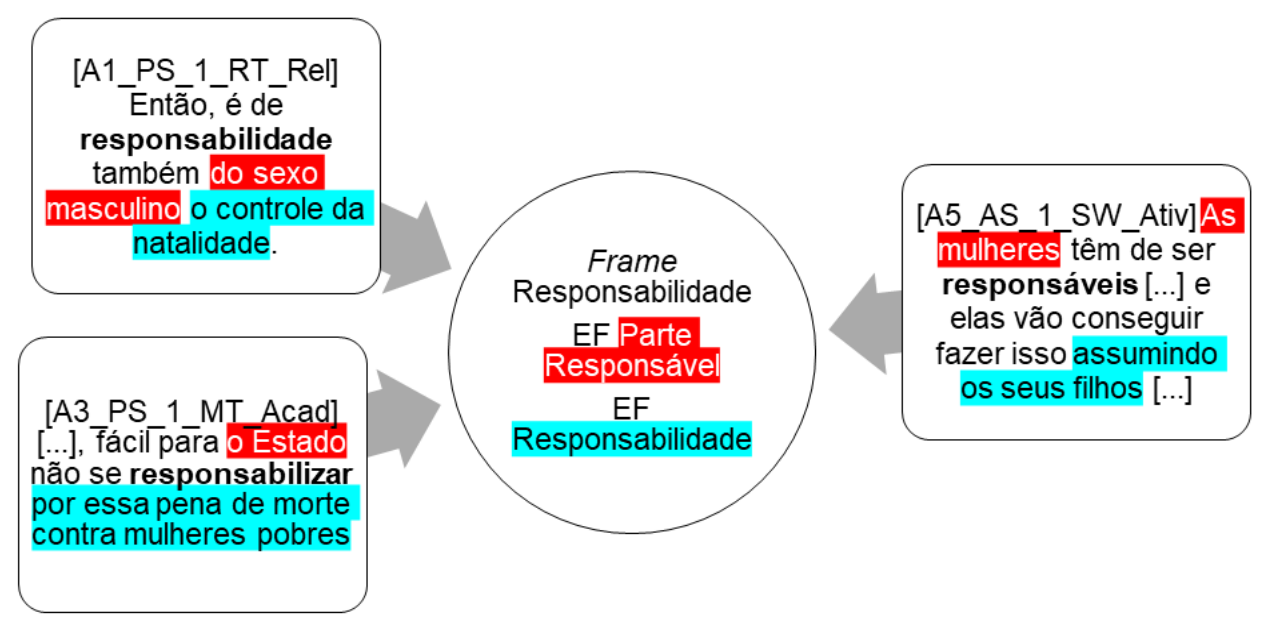

Fonte: SANTOS (2020, p. 212).

Como ilustra esse exemplo, os resultados apontaram para o agenciamento de frames que revelam conceptualizações conservadoras e/ou retrógradas sobre a mulher e seus direitos, de modo que, em vez de um avanço na discussão, tal cenário se abriu a concepções retrógradas na qual a mulher é conceptualizada como ser a quem compete utilizar meios de contracepção e evitar a gravidez indesejada, para que não se veja em uma situação de abortamento; e a quem cabe, por excelência, a responsabilidade parental sobre o feto gerado.

\section{Considerações finais}

TradTerm, São Paulo, v.37, n. 1, janeiro/2021, p. 236-264

Número Especial - Linguística de Corpus

www.revistas.usp.br/tradterm 
Este artigo discutiu alguns caminhos metodológicos que têm sido adotados para descrição de frames semânticos com base em corpora. Para isso, partimos da noção multifacetada de frame como construto sociocognitivo e como ferramenta analítica, por meio da qual é possível descrever e problematizar as conceptualizações que emergem em contextos sociais. Por meio do processo de revisão de literatura, verificamos que a pergunta de pesquisa, o tipo de corpus em estudo e o formato dos dados coletados são fatores cruciais para a definição das etapas metodológicas que permitam a aplicação do frame como ferramenta analítica em contextos sociais. Assim, tendo como base as diferentes perspectivas metodológicas encontradas na literatura, o artigo teve como ponto de chegada uma proposta delineada para uma tese de doutorado que realizou um estudo de caso baseado em um corpus de audiências públicas.

Em tal âmbito, incluímos a FrameNet no percurso metodológico, mas usando-a somente como um ponto de partida para criação de frames, tal como nos trabalhos de Lima (2009), Miranda e Loures (2016), dentre outros. Valendo-nos do direcionamento metodológico middle-out postulado pelo grupo SemanTec (CHISHMAN et al., 2018), previmos também uma etapa de estudo do domínio investigado, para então segmentar o corpus de pesquisa em temas e descrever a rede de frames que emergia dos dados. Para realizar tal segmentação, articulamos o uso de uma ferramenta de corpus (o Sketch Engine) ao NVivo, um software que permite a codificação dos dados e o cruzamento de diversos parâmetros que os classificam. Assim o corpus foi dividido em grandes temas, ou nós, processo que gerou subcorpora monotemáticos que foram processados no Sketch Engine.

Metodologicamente, acreditamos que nossa proposta contribua às pesquisas que buscam identificar frames semânticos com base em corpora, principalmente pelo fato de que nos utilizamos de dois softwares de processamento de dados que se complementam no processo de descrição de frames e auxiliam no delineamento da metodologia middle-out aqui adotada. o NVivo permitiu a segmentação de corpora em grandes temas e, assim, facilitou o processo de descrição de frames, dado que gerou subcorpora temáticos que podem ser processados em uma ferramenta de corpus. No caso

TradTerm, São Paulo, v.37, n. 1, janeiro/2021, p. 236-264 Número Especial - Linguística de Corpus www.revistas.usp.br/tradterm 
deste trabalho, valemo-nos do Sketch Engine, cuja pertinência já foi por nós corroborada em uma pesquisa com delineamentos cognitivo-discursivos (SANTOS; CHISHMAN, 2017). No entanto, é a primeira vez que utilizamos um recurso novo da ferramenta, o Sketch Difference, para comparar o uso de algumas combinatórias lexicais entre os subcorpora e atestar nossa descrição de frames. Tal recurso parece-nos pertinente para concretizar uma proposta de triangulação de dados, em que se usam diferentes métodos para "[...] revelar aspectos múltiplos de uma única realidade empírica" (SILVERMAN, 2005 , p. 35 , tradução nossa) - nesse caso, enquanto o NVivo serviu para delinearmos os frames com base em macrotemas, o Sketch Difference e outros recursos do Sketch Engine permitiram-nos confirmar ou ajustar tais descrições, com base em evidências lexicais. 


\section{Referências}

Berber Sardinha, T. Linguística de Corpus: Histórico e Problemática. D.E.L.T.A., v. 16, n. 2, p. 323-367, 2000.

ChIshman, R. et al. Field - Dicionário de Expressões do Futebol: um recurso lexicográfico baseado no aporte teórico-metodológico da Semântica de Frames e da Linguística de Corpus. Signo, Santa Cruz do Sul, v. 39, n. 67, p. 25-35, jul./dez. 2014.

ChIShman, R. A visão enciclopédica dos frames semânticos. Letrônica, Porto Alegre, v. 12, n. 2, p. 2-11, abr./jun. 2019.

CHISHMAN, R. et al. The relevance of the Sketch Engine software to build Field Football Expressions Dictionary. Revista de Estudos da Linguagem, Belo Horizonte, v. 23, n. 3, p. 769-796, 2015.

ChISHMAN, R. et al. Dicionário Olímpico: a Semântica de Frames encontra a lexicografia eletrônica. In: Finatto, M. J. B.; ReBeCHI, R. R.; SARMEnTo, S.; Bocorny, A. E. P. (org.). Linguística de Corpus: Perspectivas. Porto Alegre: Instituto de Letras - UFRGS, 2018. p. 265-298.

CHISHMAN, R. et al. Challenges and Difficulties in the Development of Dicionário Olímpico (2016). In: ELEX 2019 CONFERENCE, 2019, Sintra. Proceedings [...]. Sintra: Lexical Computing CZ s.r.o., Brno, Czech Republic, 2019. p. 622-641.

FILLMORE, C. Frame semantics and the nature of language. In: Conference on the Origin and Development of Language and Speech, 1976, New York. Proceedings... New York: New York Academy of Sciences, 1976a. p. 2032.

FILLMORE, C. J. The need for a frame semantics within linguistics. SMIL: Statistical Methods in Linguistics, Stockholm, v. 12, p. 5-29, $1976 \mathrm{~b}$.

FILLMORE, C. J. Remarks on contrastive pragmatics. In: FISIAK, J. (Ed.). Contrastive Linguistics: prospects and problems. Berlin/New York/Amsterdam: Mouton Publishers, 1980. p. 119-141.

Fillmore, C. J. Frame Semantics. In: The Linguistics SOCIETY OF KoreA (Org.). Linguistics in the Morning Calm. Seoul: Hansinh Publishing Co., 1982, p. 111-137.

FILLMORE, C. J. Frames and the semantics of understanding. Quaderni di Semantica, [s. l.], v. 6, n. 2, p. 222-254, 1985.

Fillmore, C. J.; Baker, C. A frames approach to semantic analysis. In: Heine, B.; NARRoG, H. (eds.). The Oxford Handbook of Linguistic Analysis. New York: Oxford University Press, 2010. p. 313-339.

TradTerm, São Paulo, v.37, n. 1, janeiro/2021, p. 236-264 Número Especial - Linguística de Corpus www.revistas.usp.br/tradterm 
FILlmore, C. J.; Petruck, M. R. FrameNet Glossary. International Journal of Lexicography, Oxford, v.16, n. 3, p. 359-361, 2003.

FreITAS, L. S. Gramática e manipulação: análise cognitivo-funcional de manchetes de jornais durante o segundo turno das eleições presidenciais de 2014. 2018. 149 f. Dissertação (Mestrado em Linguística) - Programa de Pós-Graduação em Linguística, Universidade de Brasília, Brasília, 2018.

GIL, A. C. Como elaborar projetos de pesquisa. 4. ed. São Paulo: Atlas, 2008.

GOFFMAN, E. Frame Analysis: an essay on the organization of experience. Cambridge: Harvard University Press, 1974.

GuIzzo, B. S.; KRZImInskI, C. O.; OLIVEIRA, D. L. C. C. O Software QSR NVIVO 2.0 na análise qualitativa de dados: ferramenta para a pesquisa em ciências humanas e da saúde. Revista Gaúcha de Enfermagem, Porto Alegre, v. 24, n. 1, p. 53-60, abr. 2003.

Hanks, W. O que é contexto. In: Bentes, A. C.; Rezende, R. C.; Machado, M. R. (Orgs.) Língua como prática social: das relações entre língua, cultura e sociedade a partir de Bourdieu e Bakhtin. São Paulo: Cortez, 2008. p. 169-203.

Jubran, C. C. A. S. Revisitando a noção de tópico discursivo. Cadernos de Estudos Linguísticos, Campinas, v. 48, n. 1, p. 33-41, 2006.

JURAFSKY, D. Charles Fillmore. Computational Linguistics, Cambridge, v. 40, n. 3, p. 725-731, 2014.

KoESTER, A. Building small specialised corpora. In: McCARTHY, M.; O'KeEfe, A. (Eds.) The Routledge handbook of Corpus Linguistics. London/New York: Routledge, 2010. p. 66-79.

LaKOFF, G. Don't think of an elephant. White River Junction: Chelsea Green Publishing, 2004.

LIMA, F. R. O. A perspectiva discente do frame aula. 2009. 148 f. Dissertação (Mestrado em Linguística) - Programa de Pós-Graduação em Linguística, Universidade Federal de Juiz de Fora, Juiz de Fora, 2009.

LIMA, F. R. O.; MIRANDA, N. S. 0 frame semântico como uma ferramenta analítica de compreensão de experiências sociais educacionais. Revista Gatilho, Juiz de Fora, v. 8, p. 1-14, 2013.

MinskY, M. A framework for representing knowledge. In: Winston, P. H. (Ed.). The psychology of computer vision. New York: McGraw-Hill Book Company, 1981.

Miranda, N. S.; Bernardo, F. C. Frames, discurso e valores. Cadernos de Estudos Linguísticos, Campinas, v. 55, n. 1, p. 81-97, 2013.

TradTerm, São Paulo, v.37, n. 1, janeiro/2021, p. 236-264 Número Especial - Linguística de Corpus www.revistas.usp.br/tradterm 
MIRANDA, N. S.; LOURES, F. C. Da análise semântica do discurso à ação educativa - um mapa da crise da sala de aula. Linguagem em (Dis)curso, Tubarão, v. 16, n. 3, p. 525-543, 2016.

MOITA LOPES, L. P. Da aplicação da Linguística à Linguística Aplicada indisciplinar. In: PeREIRA, R. C.; RocA, P. Linguística Aplicada: um caminho com diferentes acessos. São Paulo: Contexto, 2011. p. 11-24.

MORASSO, S. G. Contextual frames and their argumentative implications: A case study in media argumentation. Discourse Studies, [s.l.], v. 4, n. 2, p. 197-216, 2012.

MORATO, E. A noção de frame no contexto neurolinguístico: o que ela é capaz de explicar? Cadernos de Letras da UFF, Niterói, n. 41, p. 93-113, 2010.

MoRATO, E. et al. Processos implícitos, contextuais e multimodais na construção referencial em conversações entre afásicos e não afásicos: relato de pesquisa. Linguagem em (Dis)curso, Tubarão, v. 59, n. 1, p. 91-110, 2012.

MORATO, E. et al. O papel dos frames na construção do tópico discursivo e na coesividade comunicacional na interação entre afásicos e não afásicos. Cadernos de Estudos Linguísticos, Campinas, v. 55, n. 1, p. 91-110, 2017.

MüLleR, C. Princípios metodológicos para a construção de uma ontologia baseada na Semântica de Frames. 2015. 173 f. Tese (Doutorado em Linguística Aplicada) - Programa de Pós-Graduação em Linguística Aplicada, Universidade do Vale do Rio dos Sinos, São Leopoldo, 2015.

SANTOS, A. N. A Sugestão Legislativa $n^{\circ}$ 15/2014: entrelaçamentos e reenquadramentos de frames semânticos no debate sobre os direitos reprodutivos das mulheres no Brasil. 2020. 291f. Tese (Doutorado em Linguística Aplicada) - Programa de Pós-Graduação em Linguística Aplicada, Universidade do Vale do Rio dos Sinos, São Leopoldo, 2020. Disponível em: http:/ /www.repositorio.jesuita.org.br/handle/UNISIN OS/9111. Acesso em: 20 nov. 2020.

SANTOS, A. N. Direito, aborto e anencefalia no Brasil: uma análise semânticocognitiva do processo da ADPF-54. 2016. 2016. 161 f. Dissertação (Mestrado em Linguística Aplicada) - Programa de Pós-Graduação em Linguística Aplicada, Universidade do Vale do Rio dos Sinos (Unisinos), São Leopoldo, 2016. Disponível em: http: //www.repositorio.jesuita.or g.br/handle/UNISINOS/5203?show=full. Acesso em: 20 nov. 2020.

Santos, A. N.; ChISHMAN, R. Direito e anencefalia no Brasil: uma abordagem semântico-cognitiva da ADPF 54. Revista da Anpoll, Florianópolis, n. 42, p. 52-70, jan./jun. 2017. Disponível em: https://revistadaanpoll.emnuvens.com.br/revista/article/view/925. Acesso em: 18 ago. 2018.

TradTerm, São Paulo, v.37, n. 1, janeiro/2021, p. 236-264

Número Especial - Linguística de Corpus www.revistas.usp.br/tradterm 
SimAn, J. Frames de doença de Alzheimer. 2015. 155 f. Dissertação (Mestrado em Linguística) - Programa de Pós-Graduação em Linguística, Universidade Estadual de Campinas (Unicamp), Campinas, 2015.

SILVERMAN, D. Introducing qualitative research. In: SILVERMAN, D. (Ed.). Qualitative research: theory, method and practice. London/Thousand Oaks/New Delhi: SAGE Publications, 2005. p. 1-8.

TANNEN, D.; Wallat, C. Interactive Frames and Knowledge Schemas in Interaction: Examples from a Medical Examination/Interview. In: Tannen, D. (Ed.). Framing in Discourse. New York: Oxford University Press, 1993. p. 57-76.

TOMASELLO, M. Constructing a language: a usage-based theory of language acquisition. Cambridge, Massachusetts; London, England: Harvard University Press, 2003.

ZIEM, A. Frames of understanding in text and discourse. Amsterdam: John Benjamins, 2014.

Recebido em: $30 / 03 / 2020$

Aceito em: 05/05/2020

Publicado em janeiro de 2021

TradTerm, São Paulo, v.37, n. 1, janeiro/2021, p. 236-264

Número Especial - Linguística de Corpus www.revistas.usp.br/tradterm 